\title{
Uncoupling of disease activity and structural damage. Does it matter clinically?
}

\author{
Edith Villeneuve, Boulos Haraoui
}

Rheumatoid arthritis (RA) is an autoimmune disease characterised by synovial inflammation that can lead to joint damage through bone and cartilage destruction, loss of function and decreased quality of life. Fortunately, over the past few years, we have witnessed major advances in the management of RA with new agents and treatment strategies that have improved outcomes and made remission become a realistic goal. True remission has been defined as a state where there is no evidence of disease activity with complete resolution of signs and symptoms as well as arrest of joint damage and disability progression. Hence, inhibition of radiographic progression has become a major therapeutic goal given its direct relationship to patient function and quality of life. ${ }^{1}$ Clinical remission can be achieved with disease-modifying antirheumatic drugs (DMARD) alone or may need a combination of DMARDs and biologic agents. Radiographic remission is more complex as we have learned from the probability plots that the mean/median change of radiographic progression is accounted for by a minority of patients who progress radiographically. Indeed, regardless of the therapy used, approximately $50 \%$ of patients will not show radiographic progression over 2-3 years; This percentage increases up to $75-85 \%$ of patients receiving combination therapy, and those who do progress, progress less than patients on methotrexate alone. ${ }^{2}$

It has long been thought that prevention of radiographic progression was achieved through the eradication of synovial inflammation, and that antitumour necrosis factor (TNF) agents were more effective at reducing structural progression through a better control of inflammation. However,

Department of Rheumatology, Université de Montréal, Montreal, Canada

Correspondence to Dr Boulos Haraoui, Department of Rheumatology, University of Montreal, Institut de rhumatologie de Montréal, 1551 Ontario est, Montreal, Quebec, Canada H2L 1S6;

bharaoui@videotron.ca recent posthoc analyses have shown a disconnect between clinical and radiographic outcomes where inhibition of radiographic progression was achieved even in patients with significant residual disease activity treated with TNF inhibitors suggesting a separate direct role for TNF on bone damage. ${ }^{3-5}$ Interestingly, Aletaha and colleagues have demonstrated a similar dissociation between clinical and structural outcomes in patients treated with rituximab suggesting that the mechanism explaining this dissociation is not unique to anti-TNF drugs. ${ }^{6}$

The Anti-TNF- $\alpha$ Trial in Rheumatoid Arthritis with Concomitant Therapy (ATTRACT) was the first study to suggest the notion of disconnect, or uncoupling, between damage and inflammation when they showed a reduction in total sharp score in RA patients treated with a combination of infliximab and methotrexate who showed no improvement in tender and swollen joint counts, health assessment questionnaire (HAQ) score, patient global score and C-reactive protein (CRP) compared with patients on methotrexate and placebo. ${ }^{5}$ Similar findings have been shown in early RA and with other anti-TNF agents. ${ }^{3} 8$ This suggests that there may be a requirement for a higher TNF level threshold for induction of joint damage than for signs and symptoms, or that the biological processes leading to symptoms are not the same and less driven by TNF than those causing radiographic progression. TNF is thought to cause erosion mainly by its ability to promote the synthesis of receptor activator of nuclear factor kappa-B ligand (RANKL) which, in turn, activates the maturation of osteoclasts that leads to bone erosions. It has indeed been shown that denosumab, an anti-RANKL monoclonal antibody, reduces structural damage in RA while having no effect on clinical symptoms. ${ }^{9}$ More recently, a similar effect was demonstrated with tocilizumab which inhibits IL-6, a cytokine involved in the activation of osteoclasts. ${ }^{10}$ It is possible that the level of TNF or IL- 6 required to induce joint damage is greater than the one needed to promote clinically detectable synovitis.

However, the explanation may be more complex as the dissociation between clinical and radiographic outcomes also seems to occur when targeting upstream mechanisms such as B-cell depletion with rituximab. Using data from the A Study to Evaluate Rituximab in Combination With Methotrexate in MethotrexateNaive Patients With Active Rheumatoid Arthritis (IMAGE) trial, Aletaha et al have shown that the combination of rituximab and methotrexate retards joint damage independently of disease activity, while methotrexate retards joint damage only in patients who had a good clinical response. ${ }^{6}$ An interesting finding that was not looked for in many of the studies using TNF inhibitors is that this effect was true for both the erosion and the joint space narrowing score, and was consistent when they matched patients for disease activity. As rituximab targets $\mathrm{B}$-cells which are at the beginning of the inflammatory cascade leading to the development of RA, it seems harder to explain why it does not produce the same effect on inflammation and bone damage.

In order to explain this dissociation, Watson et al proposed a 'twocompartment model' with centres of pathology in both bone and synovium. ${ }^{11}$ Autoreactive B cells escape deletion in the bone marrow and migrate to either the synovium leading to synovitis or to subchondral bone where they will lead to osteitis and, eventually, bone erosion. Indeed, imaging studies have shown that the best predictor of radiographic progression is not MRI synovitis but bone marrow oedema which correlates with osteitis. ${ }^{12}$ Once initiated, it could be that the biologic processes occurring at each site are different with predominance for $B$ cells in the bone, and possibly more T cells in the synovium explaining the effect of rituximab on damage even in patients without clinical improvement. Supporting this hypothesis, a study looking at the cellular components of bone oedema, known to be an important predictor of bone erosion, found that these were made predominantly of osteoclasts with a trend for more plasma cells and aggregates of $\mathrm{B}$ cells. ${ }^{13} \mathrm{On}$ the opposite side, in a small study examining synovial tissue from five RA patients, $75-90 \%$ of lymphocytes present were identified as T cells. ${ }^{14}$ When comparing the cellular composition of bone marrow aggregates with synovial tissue, JimenezBoj and colleagues have also demonstrated 
a higher number of $\mathrm{B}$ cells in the bone marrow aggregates and similar number of Tcells. $^{15}$

Finally, these novel findings are mainly interesting because of their clinical implications. As recommend by an expert task force, most rheumatologists now treat their patients to a target which should be remission or low disease activity. ${ }^{16}$ These recommendations, as well others developed by the different national organizations, ${ }^{17} 18$ should definitely be implemented in all patients, especially those treated with methotrexate (MTX) or the traditional DMARDs, who display more radiographic damage despite good clinical control. ${ }^{19}$ However, results from this trial, and others with TNF inhibitors, suggest that this target may not have to be the same for patients on biologics than conventional DMARDs. We need to be more stringent for patients on methotrexate, while low disease activity may be adequate for patients on biologics since little structural damage will occur. There would also be less urgency to switch treatment in patients on biologics who are partial responders than if on methotrexate only. However, we should still aim at suppression of clinical symptoms as they are what affect patients most on a daily basis, and change treatment in patients with suboptimal clinical response despite the potential prevention of bone damage.

However, several issues remain; the majority of the recent clinical trials, including this one, have demonstrated very little radiographic progression. ${ }^{6} 20$ Should we start using more sensitive techniques to evaluate structural damage, such as ultrasound, computerised tomography or MRI which will not only assess the structural damage but also residual inflammation in the synovium and bone that can lead to cartilage and bone lesions? Should these new imaging modalities be incorporated in the definition of remission? We would then need to define the threshold of imaging activity that will be clinically relevant.

Funding None.
Competing interests None.

Provenance and peer review Commissioned externally peer reviewed.

Accepted 25 October 2012

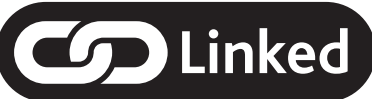

- http://dx.doi.org/10.1136/annrheumdis-2012-201970

Ann Rheum Dis 2013:72:1-2.

doi:10.1136/annrheumdis-2012-202650

\section{REFERENCES}

1. Lillegraven $\mathbf{S}$, van der Heijde $\mathrm{D}$, Uhlig T, et al. What is the clinical relevance of erosions and joint space narrowing in RA? Nat Rev Rheumatol 2012;8:117-20.

2. Keystone $\mathbf{E}$. Recent concepts in the inhibition of radiographic progression with biologics. Curr Opin Rheum 2009;21:231-7.

3. Landewe R, van der Heijde D, Klareskog L, et al. Disconnect between inflammation and joint destruction after treatment with etanercept plus methotrexate. Arthritis Rheum 2006;54:3119-25.

4. Smolen JS, van der Heijde DM, Keystone EC, et al. Association of joint space narrowing with impairment of physical function and work ability in patients with early rheumatoid arthritis: protection beyond disease control by adalimumab plus methotrexate. Ann Rheum Dis 2012. Published Online First 22 Aug 2012

5. Smolen JS, Han C, Bala M, et al. for the ATTRACT Study Group. Evidence of radiographic benefit of treatment with infliximab plus methotrexate in rheumatoid arthritis patients who had no clinical improvement: a detailed subanalysis of data from the anti-tumor necrosis factor trial in rheumatoid arthritis with concomitant therapy study. Arthritis Rheum 2005; 52:1020-30.

6. Aletaha D, Alasti F, Smolen JS. Rituximab dissociates the tight link between disease activity and joint damage in rheumatoid arthritis patients. Ann Rheum Dis 2012. Published Online First 21 Aug 2012

7. Smolen JS, van der Heijde DM, St. Clair EW, et al. Predictors of joint damage in patients with early rheumatoid arthritis treated with high-dose methotrexate without or with concomitant infliximab. Results from the ASPIRE trial. Arthritis Rheum 2006;54:702-10.

8. Emery $\mathbf{P}$, Genovese MC, van Vollenhoven $\mathrm{R}$, et al. Less radiographic progression with adalimumab plus methotrexate versus methotrexate monotherapy across the spectrum of clinical response in early rheumatoid arthritis. J Rheumatol 2009;36:1429-41.

9. Cohen SB, Dore RK, Lane NE, et al. for the Denosumab Rheumatoid Arthritis Study Group. Denosumab treatment effects on structural damage, bone mineral density, and bone turnover in rheumatoid arthritis: a twelve-month, multicenter, randomized, double-blind, placebo-controlled, phase II clinical trial. Arthritis Rheum 2008;58:1299-309.

10. Smolen JS, Martinez Avila JC, Aletaha D. Tocilizumab inhibits progression of joint damage in rheumatoid arthritis irrespective of its anti-inflammatory effects: disassociation of the link between inflammation and destruction. Ann Rheum Dis 2012;71:687-93

11. Watson WC, Tooms RE, Carnesale PG, et al. A case of germinal center formation by CD45RO T and CD20 B lymphocytes in rheumatoid arthritic subchondral bone: proposal for a two-compartment model of immune-mediated disease with implications for immunotherapeutic strategies. Clin Immunol Immunopathol 1994;73:27-37.

12. Haavardsholm EA, Bøyesen $\mathrm{P}$, Østergaard $\mathrm{M}$, et al. Magnetic resonance imaging findings in 84 patients with early rheumatoid arthritis: bone marrow oedema predicts erosive progression. Ann Rheum Dis 2008;67:794-800.

13. Dalbeth N, Smith T, Gray S, et al. Cellular characterization of magnetic resonance imaging bone oedema in rheumatoid arthritis; implications for pathogenesis of erosive disease. Ann Rheum Dis 2009;68:279-82.

14. Bankhurst AD, Husby G, Williams RC Jr. Predominance of $\mathrm{T}$ cells in the lymphocytic infiltrates of synovial tissues in rheumatoid arthritis. Arthritis Rheum 2008;58(2 issue):S58-65.

15. Jimenez-Boj $\mathbf{E}$, Redlich $\mathrm{K}$, Türk B, et al. Interaction between synovial inflammatory tissue and bone marrow in rheumatoid arthritis. $\mathrm{J} / \mathrm{mmunol}$ 2005:175:2579-88.

16. Smolen JS, Aletaha D, Bijlsma JW, et al. for the T2T Expert Committee. Treating rheumatoid arthritis to target: recommendations of an international task force. Ann Rheum Dis 2010;69:631-7.

17. Singh JA, Furst DE, Bharat A, et al. 2012 update of the 2008 American College of Rheumatology recommendations for the use of disease-modifying antirheumatic drugs and biologic agents in the treatment of rheumatoid arthritis. Arthritis Care Res (Hoboken) 2012;64:625-39.

18. Smolen JS, Landewé R, Breedveld FC, et al. EULAR recommendations for the management of rheumatoid arthritis with synthetic and biological disease-modifying antirheumatic drugs. Ann Rheum Dis 2010;69:964-75

19. Goekoop-Ruiterman YP, de Vries-Bouwstra JK, Allaart CF, et al. Clinical and radiographic outcomes of four different treatment strategies in patients with early rheumatoid arthritis (the BeSt study): a randomized, controlled trial. Arthritis Rheum 2005; 52:3381-90.

20. Emery $\mathbf{P}$, Fleischmann R, van der Heijde D, et al. The effects of golimumab on radiographic progression in rheumatoid arthritis: results of randomized controlled studies of golimumab before methotrexate therapy and golimumab after methotrexate therapy. Arthritis Rheum 2011:63:1200-10. 